\title{
Molecular Characterization of Salmonella Isolates of Duck in Comparison to Salmonella Isolates of Chicken and Ruminants
}

\author{
Tania Mondal ${ }^{1}$, M Shahidur Rahman Khan ${ }^{1 *}$, Munirul Alam² and Moushumi Purakayastha ${ }^{1}$ \\ ${ }^{1}$ Department of Microbiology \& Hygiene, Faculty of Veterinary Science, Bangladesh Agricultural University, Mymensingh 2202, Bangladesh, ${ }^{2}$ Enteric \\ Microbiology Laboratory, Laboratory Sciences Division, Centre for Health \& Population Research, International Centre for Diarrhoeal Disease \\ Research, Bangladesh (ICDDR,B), GPO Box 128, Mohakhali, Dhaka 1212, Bangladesh
}

[Received 31 July 2008; Accepted 07 November, 2009]

\begin{abstract}
Salmonella species are recognized as a major cause of food borne illness that are closely associated with the consumption of contaminated poultry and egg products. The present study was conducted to compare the cultural, biochemical characteristics, antibiotic sensitivity pattern and the patterns of genomic organization of duck Salmonella isolates associated with chicken, cattle, sheep and goat using pulsed-field gel electrophoresis (PFGE) with Xba1 restriction enzyme. The comparative antibiogram study among duck, chicken and ruminants showed variable results in antibiotic sensitivity and similar results in resistance pattern. Genome analysis using PFGE with Xba1 restriction enzyme revealed that the Salmonella isolates of the same species collected from same areas to be of same genomic pattern, although a great genomic diversity could be found among duck, chicken, sheep, goat and cattle Salmonella strains. It may be concluded from the result of this research work that the heterogeneity in genomic organization among different isolates of different species collected from different areas occurred greatly and for this reason.
\end{abstract}

Keywords: Salmonellosis, Salmonella, Pulsed-field gel electrophoresis (PFGE), Duck, Chicken, Ruminants

\section{Introduction}

Salmonellosis is a disease of human beings, cattle, sheep, goat, pigs and chicken including duck and is manifested clinically in all hosts by one of three major syndromes: a peracute systemic infection, acute enteritis or chronic enteritis. But the clinical signs may vary from species to species ${ }^{1}$. Human infections with Salmonella have been increasing worldwide since 1980 and have been shown to be related mainly to consumption of eggs and egg products $^{2-3}$. On the other hand, S. blockley, S. weltevreden, and S. amsterdam have been identified as common serovars found in broilers, layers, and breeder parent stock, respectively, and Salmonella has been detected in eggs from layers, according to a Thai report ${ }^{4}$. Furthermore, $S$. enteritidis has been isolated from chicken feces and chicken meat in Thailand ${ }^{5-6}$. However, the relationship between human infections and isolates of $S$. enteritidis from broiler chicken meat remains obscure.

The members of the genus Salmonella are being isolated, identified and characterized by using various cultural, biochemical, serological and molecular studies. The reliable methods for isolation require the use of media, which encourage the growth of Salmonella and inhibit that of other enteric organisms. A great variety of fluid and solid enrichment and selective media such as selenite broth, Salmonella-Shigella (SS) agar, MacConkey agar, brilliant green agar (BGA) have been used for this purpose. Antibiogram study, serum agglutination test, pathogenicity test, enzyme-linked immunosorbent assay (ELISA), polymerase chain reaction (PCR), DNA-DNA hybridization, pulsed-field gel electrophoresis (PFGE) are widely being used to identify and characterize Salmonella spp. in the laboratories ${ }^{7-9}$.

For the molecular characterization, PFGE is an important tool for the analysis of the genomic organization of different species of Salmonella, which is used to explain the genomic basis of the epidemic ${ }^{10-11}$. In this study, isolation, identification and characterization of duck Salmonella in comparison to chicken, cattle, sheep, and goat Salmonella isolates from various locations were analyzed via PFGE with Xba1 to compare genomic organizations of different serotypes of different species. PFGE using Xba1 restriction provided a possible alternative method for screening and identifying duck Salmonella serotypes in comparison to other serotypes previously isolated from chicken, cattle, sheep and goat.

\section{Materials and Methods}

Laboratory and specimens

The experiment was conducted between November 2006 and October 2007 in the Bacteriology Laboratory of the Department of Microbiology and Hygiene, Bangladesh Agricultural University 
(BAU), Mymensingh and Enteric Microbiology Laboratory, International Centre for Diarrhoeal Diseases Research of Bangladesh (ICDDR,B) in Dhaka. A total of 65 cloacal swab samples from apparently healthy and diarrhoeic ducks were tested for the examination. In addition, 27 isolates of Salmonella from chicken, cattle, sheep and goat collected from the repository of the Department of Microbiology and Hygiene, BAU, Mymensingh were used to compare with those of ducks.

\section{Cultivation and isolation of Salmonella}

Cloacal swabs were collected and each of swabs was inoculated into freshly prepared selenite broth. Then the tubes were marked properly and incubated at $37^{\circ} \mathrm{C}$ for $24 \mathrm{~h}$ aerobically in bacteriological incubator. The tubes were then examined for growth of bacteria. Smears were prepared for each culture and the Gram-stained examined under microscope. Gram-negative rod isolates were streaked on MacConkey agar, Salmonella-Shigella agar and brilliant green agar separately. The plates were then incubated at $37^{\circ} \mathrm{C}$ for $24 \mathrm{~h}$. The plates containing characteristic colonies of Salmonella were selected. Motility test and Gramreaction were performed to identify Salmonella. Subculturing in Salmonella-Shigella agar was performed from the suspected plates containing Salmonella to obtain a pure culture ${ }^{12}$. These pure isolates obtained in this way were used for further study.

\section{Biochemical characterization}

Organisms showing cultural characteristics of Salmonella on various media were maintained on SS and BGA and were subjected to biochemical tests such as sugar fermentation test, MR-VP reaction and indole reaction.

\section{Antibiogram study of Salmonella isolates}

Susceptibility of the Salmonella isolates to different antibacterial agents was performed through disc diffusion method ${ }^{13}$. In this method Salmonella isolates were grown overnight on BGA. The overnight cultured isolates were inoculated into NB and poured on BGA and spread uniformly with the help of sterile glass spreader. Antibacterial discs were applied aseptically to the surface of the plate at an appropriate arrangement with the help of sterile forceps and incubated aerobically at $37^{\circ} \mathrm{C}$ for $24 \mathrm{~h}^{14}$.

\section{Maintenance of stock culture}

Salmonella isolates from duck and the laboratory isolates of Salmonella from chicken, cattle, sheep and goat were preserved in $20 \%$ glycerine and soft agar method. Salmonella isolates preserved in $20 \%$ glycerine were placed in ice box and transported to ICDDR,B, Dhaka for performing molecular characterization.
Molecular typing of Salmonella by pulsed-field gel electrophoresis (PFGE)

Molecular typing of Salmonella isolates by PFGE was done using preparation of PFGE agarose plugs from cell suspensions and lysis of cells in agarose plugs. After cell lysis agarose plugs were washed and then subjected to restriction digestion of DNA in agarose plugs with Xba1 followed by casting agarose gel and loading restriction plug slices on the comb. Electrophoresis was performed with the contour clamped homogenous electric field (CHEF-DRII) apparatus from the Bio-Rad (Richmond, USA).

\section{Results and Discussion}

Around the world, Salmonella is the most important agent causing food-borne illness, with Salmonella enterica serovar Enteritidis and Salmonella serovar Typhimurium predominating ${ }^{15}$. Salmonella is a pathogen of both humans and animals. This organism has caused outbreaks of human disease both in developed ${ }^{16-17}$ and developing ${ }^{18}$ countries. A Danish surveillance program for Salmonella in fresh meat, instituted after an epidemic of Salmonella, found 3.1\% of pork cuts were contaminated with Salmonella serotype Infantis ${ }^{19}$. Isolates from a cattle outbreak of Salmonella associated with contaminated feed in Finland were analyzed by pulsed-field gel electrophoresis (PFGE), plasmid analysis, ribotyping, and IS200 typing ${ }^{20}$. The disease burden in terms of sporadic cases due to Salmonella of animal origin to human disease is not known in Bangladesh. In this study an attempt was made to compare Salmonella isolates of livestock including duck, chicken, cattle, sheep and goat.

In this study, all Salmonella isolates from duck, chicken, cattle, sheep and goat showed similar colony characteristics on Salmonella-Shigella, MacConkey and BrilliantGreen agar media. All isolates showed similar staining characteristics, i.e., Gramnegative, short rod shaped organisms. All of the isolates exception for the chicken isolates showed positive motility test. After biochemical examination it was observed that all the isolates fermented dextrose, maltose and mannitol and produced acid and gas but did not ferment lactose and sucrose. They were negative to VogesProskauer test and indole test with the exception of a few isolates (viz., D1Fa, D6Bb and Ch7Fg) but all isolates showed positive result to methyl red test.

Comparative antibiogram results of duck Salmonella isolates and chicken and ruminants isolates are summarized in Table 1 . The isolates of duck and ruminants were found resistant to chloramphenicol, whereas the isolates of chicken were found resistant to chloramphenicol and amoxicillin.

Table 1. Comparative antibiotic sensitivity pattern of Salmonella isolates from various sources

\begin{tabular}{lcccc}
\hline Source of Salmonella & Highly sensitivity & Moderately sensitivity & Less sensitivity & Resistance \\
\hline Duck & CIP, K, NA, SxT, CL & K, NA, SxT, CL, E, AML & E, AML, C & C \\
Chicken & CIP, K, NA & SxT, CL & E & AML, C \\
Ruminant & CIP, K, NA, SxT & CL & E, AML & C \\
\hline
\end{tabular}

$\mathrm{AML}=$ Amoxicillin, $10 \mu \mathrm{g}$; C = Chloramphenicol, $30 \mu \mathrm{g}$; CIP = Ciprofloxacin, $5 \mu \mathrm{g}$; CL = Cephalexin, $30 \mu \mathrm{g}$;

$\mathrm{E}=$ Erythromycin, $10 \mu \mathrm{g} ; \mathrm{K}$ = Kanamycin, $30 \mu \mathrm{g}$; NA = Nalidixic acid, $30 \mu \mathrm{g}$; SxT= Cotrimoxazole, $25 \mu \mathrm{g}$. 
Pulsed-field gel electrophoresis (PFGE) based on analysis of the whole genome by restriction endonuclease digestion might also be useful for investigation of sources of salmonellosis ${ }^{21}$. In this study, PFGE analysis of the Xba1 digested chromosomal DNA of the Salmonella isolates yielded 12 to 17 reproducible DNA fragments ranging in size of approximately from $<20$ to $<668.9 \mathrm{kbp}$ (Figure 1). PFGE analysis revealed that Salmonella isolates $(\mathrm{n}=13)$ from the same origin displayed very similar restriction fingerprint pattern, while the isolates of different species of different places yielded diverse and heterogeneous banding pattern.

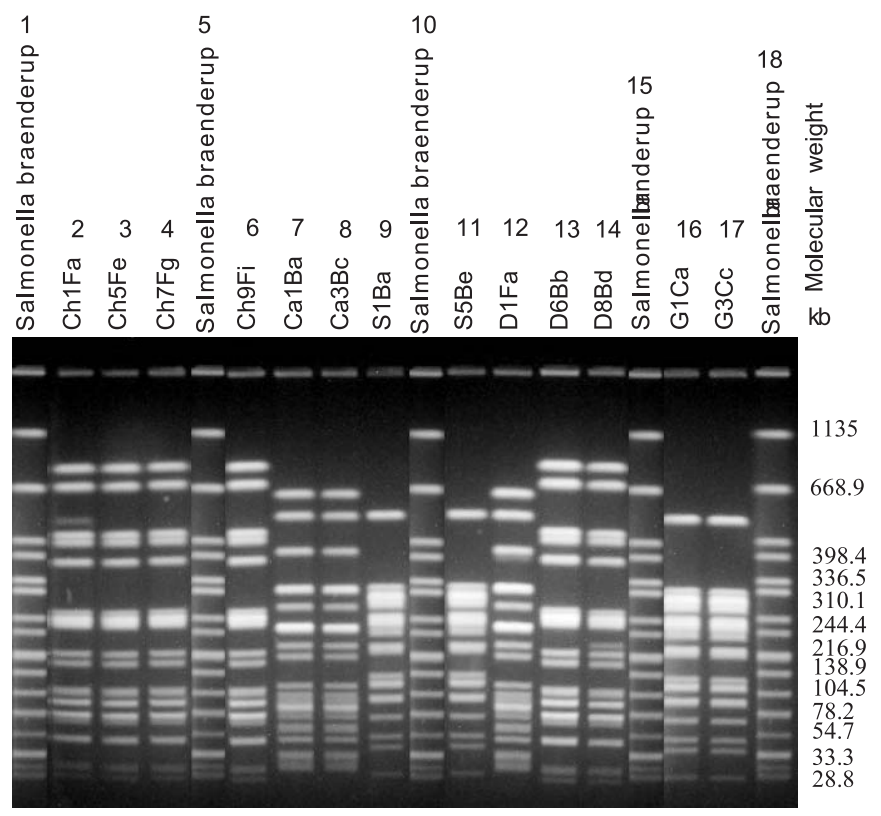

Figure 1. Pulsed-field gel electrophoresis (PFGE) with Xba1 of Salmonella isolates from chicken, cattle, sheep, duck and goat. Lane 1, 5, 10, 15 and 18 = Genomic organization of Salmonella braenderup used as a marker. Lane 2, 3, 4 and $6=$ Genomic organizations of chicken isolates collected from BAU Poultry Farm; Lane 7 and $8=$ Genomic organizations of cattle isolates collected from Boyra, Mymensingh; Lane 9 and $11=$ Genomic organizations of sheep isolates collected from Boyra, Mymensingh; Lane 12 = Genomic organization of duck isolates collected from BAU Poultry Farm; Lane 13 and $14=$ Genomic organization of duck isolates collected from Boyra, Mymensingh; Lane 16 and 17 = Genomic organizations of goat isolates collected from Char Nilokkhiya.

The present study showed, interestingly, that the Salmonella isolates of different lifestock produced different PFGE pattern. However, Thong et al..$^{22}$ and Boonmar et al. ${ }^{23}$ observed that the isolates of different phage types produced the same PFGE pattern. Some studies have implicated poultry and poultry product (e.g., egg) contamination as the primary cause of increased Salmonella infection in humans ${ }^{24-25}$. It has also been reported that the phage type distribution in isolates originating from the meat of broiler chickens is similar to that in human isolates. The evidence presented here indicates that meat products could be a potential source of human infection by Salmonella. PFGE is required for an adequate description of the strain characteristics of Salmonella from various sources. Continued epidemiological and laboratory monitoring of changes in the background of sporadic human cases, especially of uncommon strains, will further define the scope of the problem.

\section{References}

1. Radostits OM, Gay CC, Blood DC \& Hinchcliff KW. 2000. Veterinary Medicine: A Textbook of the Diseases of Cattle, Sheep, Pigs, Goats and Horses, $9^{\text {th }}$ edn, pp 809-829. WB Saunders Co, London.

2. CDC. 1998. Standardized molecular subtyping of foodborne bacterial pathogens by pulsed-field gel electrophoresis. The National Molecular Subtyping Network for Foodborne Disease Surveillance, Centers for Disease Control and Prevention (CDC), Atlanta.

3. Khakhria R, Woodward D, Johnson WM \& Poppe C. 1997. Salmonella isolated from humans, animals, and other sources in Canada, 1982-92. Epidemiol Infect. 119: 15-23.

4. Mead PS, Slutsker L, Dietz V, McCaig LF, Bresee JS, Shapiro C, Griffin PM \& Tauxe RV. 1999. Food-related illness and death in the United States. Emerg Infect Dis. 5: 607-625.

5. Anderson ES \& Williams REO. 1956. Bacteriophage typing of enteric pathogens and Staphylococci and its use in epidemiology. J Clin Pathol. 9: $94-127$.

6. Cuff W, Khakhria R, Woodward DL, Ahmed R, Clark CG \& Rodgers FG. 2001. Enteric pathogens identified in Canada: annual summary 1998. Laboratory Centre for Disease Control, Winnipeg, Manitoba.

7. Deignan T, Alwan A, Kelly J, McNair J, Warren T \& O’Farrelly C. 2000. Serum haptoglobin: An objective indicator of experimentallyinduced Salmonella infection in calves. Res Vet Sci. 69(2): 153-158.

8. Veling J, van Zijderveld FG, van Zijderveld-van Bemmel AM, Barkema HW \& Schukken YH. 2000. Evaluation of three newly developed enzyme-linked immunosorbent assays and two agglutination tests for detecting Salmonella enterica subsp. enterica serovar Dublin infections in dairy cattle. J Clin Microbiol. 38: 4402-4407.

9. Buerfeind R, Barth S, Weiss R \& Baljer G. 2001. Prevalence of the Salmonella plasmid virulence gene "spvD" in Salmonella strains from animals. Dtsch Tierarztl Wochenschr. 108(6): 243-245.

10. Izumiya H, Terajima J, Matsushita S, Tamura K \& Watanabe H. 2001. Characterization of multidrug-resistant Salmonella enterica serovar Typhimurium isolated in Japan. J Clin Microbiol. 39(7): 2700-2703.

11. Tamada Y, Nakaoka Y, Nishimori K, Doi A, Kumaki T, Uemura N, Tanaka K, Makino SI, Sameshima, T, Akiba M, Nakazawa M \& Uchida I. 2001. Molecular typing and epidemiological study of Salmonella enterica serotype Typhimurium isolates from cattle by fluorescent amplified-fragment length polymorphism fingerprinting and pulsedfield gel electrophoresis. J Clin Microbiol. 39(3): 1057-1066.

12. Cheesbrough M. 1985. Medical Laboratory Manual for Tropical Countries, Vol 2: Microbiology, pp 400-480. Thetfort Press Ltd, Cambridgeshire.

13. Bauer AW, Kirby WM, Secherris JC \& Turek M. 1966. Antibiotic susceptibility testing by standard single disc method. Am J Clin Pathol. 45(4): 493-496.

14. Carter GR. 1979. Diagnostic Procedures in Veterinary Bacteriology and Mycoplasma, $3^{\text {rd }}$ edn, pp 398-417. Charles Thomas Publisher, Illinois

15. Todd EC. 1997. Epidemiology of foodborne diseases: A worldwide review. World Health Stat Q. 50: 30-50.

16. Meehan PJ, Atkeson T, Kepner DE \& Melton MA. 1992. Foodborne outbreak of gastroenteritis involving two different pathogens. Am J Epidemiol. 136: 611-616. 
17. Page WE, Shimes V \& Vair L. 1988. Salmonella infantis in a hospital obstetrical department-Ontario. Canada Dis Wkly Rep. 14: 42-43.

18. Ngoma M, Pandey GS, Suzuki A, Sato G \& Chimana H. 1996. Prevalence of Salmonella in apparently healthy slaughtered cattle and pigs in Zambia. Indian J Anim Health. 35: 197-200.

19. Sørensen LL \& Bager F. 1995. Salmonella-forekomst i svinekød 1993-1994. Dansk Veterincertidsskr. 78: 159-162.

20. Lindqvist N, Heinikainen S, Toivonen A-M \& Pelkonen S. 1999. Discrimination between endemic and feedborne Salmonella Infantis infection in cattle by molecular typing. Epidemiol Infect. 122: 497504.

21. Powell NG, Threlfall EJ, Chart H \& Rowe B. 1994. Subdivision of Salmonella enteritidis PT 4 by pulsed-field gel electrophoresis: Potential for epidemiological surveillance. FEMS Microbiol. 119: 193-198.
22. Thong KL, Ngeow YF, Altwegg M, Navaratnam P \& Pang T. 1995. Molecular analysis of Salmonella enteritidis by pulsed-field gel electrophoresis and ribotyping. J Clin Microbiol. 33: 1070-1074.

23. Boonmar S, Bangtrakulnonth A, Pornrunangwong S, Terajima J, Watanabe H, Kaneko K-I \& Ogawa M. 1998. Epidemiological analysis of Salmonella enteritidis isolates from humans and broiler chickens in Thailand by phage typing and pulsed-field gel electrophoresis. J Clin Microbiol. 36(4): 971-974.

24. Humphrey TJ, Cruickshank JG \& Rowe B. 1989. Salmonella enteritidis phage type 4 and hens' eggs. Lancet. 1(8632): 280-281.

25. Rodrigue DC, Tauxe RV \& Rowe B. 1990. International increase in Salmonella enteritidis: A new pandemic? Epidemiol Infect. 105: 2127. 